Research Peper:

\title{
A Partial Examination of the Emotion Dysregulation Model of Distress Symptoms in an Iranian Community Sample
}

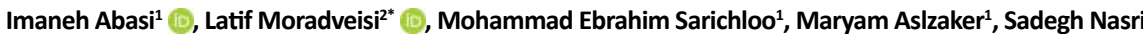

1. Department of Clinical Psychology, University of Social Welfare and Rehabilitation Sciences, Tehran, Iran.

2. Research Center for Behavioral Disorders and Substance Abuse, Hamadan University of Medical Sciences, Hamadan, Iran.

3. Department of Education and Psychology, Faculty of Humanities, Shahid Rajaee Teacher Training University, Tehran, Iran.

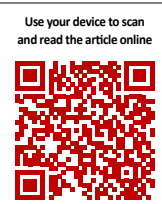

Cftation Abasi I, Moradveisi L, Sarichloo ME, Aslzaker M, Nasri S. A Partial Examination of the Emotion Dysregulation Model of Distress Symptoms in an Iranian Community Sample. Avicenna Journal of Neuropsychophysiology. 2018; 5(1):11-18. http:// dx.doi.org/10.32598/ajnpp.5.1.11

http://dx.doi.org/10.32598/ajnpp.5.1.11

Article info:

Received: 25 Jun 2018

Accepted: 05 Nov 2018

Available Online: 01 Feb 2018
Keywords:

Emotion, Motivation,

Anxiety, Depression

\section{A B S T RACT}

Background: The comorbidity of generalized anxiety and major depressive disorders and the challenges of distress disorders create a model such as emotion dysregulation.

Objectives: The present study aimed at examining the emotion dysregulation model of distress symptoms in a community sample.

Materials and Methods: A total of 508 individuals were recruited from a community sample, using convenience sampling method. The participants filled in the questionnaires that assess their safety motivation and emotional intensity, emotion regulation strategies (attentional control, acceptance, decentering, and reappraisal), and distress symptoms (depression, generalized anxiety symptoms, worry, and rumination). The structural equation modeling was used to assess the fitness model.

Results: The model yielded a good fitness $\left(\chi^{2}=64.51, d f=26, \chi^{2} / d f=2.48, P<0.001, C F I=0.97\right.$, $\mathrm{GFI}=0.97, \mathrm{PCFI}=0.56$, and RMSEA=0.05). The emotion dysregulation model of distress symptoms has an acceptable fitness.

Conclusion: The mediating role of emotion regulation strategies in this model highlights the important effects of emotion regulation abilities in protecting individuals suffering from distress symptoms.

\section{* Corresponding Author:}

Latif Moradveisi, PhD.

Address: Research Center for Behavioral Disorders and Substance Abuse, Hamadan University of Medical Sciences, Hamadan, Iran.

Tel: +98 (813) 8271066

E-mail: latif.moradveisi@gmail.com 


\section{Introduction}

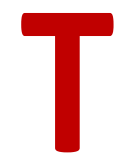

here is a high comorbidity between Generalized Anxiety Disorder (GAD) and Major Depressive Disorder (MDD) in the clinical and non-clinical population [1-3]. Several researchers found a high genetic correlation between MDD and GAD [4, 5]. Other family members and twin studies indicate that MDD shares more genetic factors with $G A D$ than other anxiety disorders $[5,6]$. Also, because of genetic substrate similarities, some authors recommend that these two disorders should be classified into one category [5].

The co-occurrence of MDD and GAD can damage individuals' functions in daily life. However, comorbidity of MDD and GAD is associated with poorer prognosis, lower health-related quality of life and general quality of life, higher symptom severity, and lower rates of response to treatment [7-12].

Recently, more attention has been paid to the comorbidity of MDD and GAD, in which emotion regulation, as a mediator alone or in combination with other personality factors, predispose individuals to emotional disorders, especially distress disorders [13-18]. Concerning the common mechanism of depression and anxiety comorbidity, especially GAD and MDD, several models have been proposed $[19,20]$. One of the distinguished integrative models is emotion dysregulation model. This model tries to explain the responsible mechanism of comorbidity between GAD and MDD and has emphasized distress disorders $[15,16]$.

In emotion dysregulation model, negative self-referential processing (worry and rumination) along with MDD and GAD symptoms are called distress symptoms [16]. Furthermore, one of the common characteristics of comorbid and refractory disorders like distress disorders is emotional intensity/neuroticism/emotionality $[16,21]$. Neuroticism is an efficient marker of nonspecific risk factor, and disorders with a substantial amount of this feature are categorized as emotional disorders $[22,23]$. The heightened intensity of motivational impetus like the necessity to avoid the threat or heightened sensitivity to punishment is another factor of emotion dysregulation model [16]. The second mediating component is an emotion regulation strategy. Individuals with distress symptoms cannot often use emotion regulation strategies flexibly in the appropriate context and MDD [21, 24-26].
Emotion dysregulation model postulates that individuals with distress disorders possess imbalanced and heightened motivational system and emotional intensity. Thus, individuals with emotion regulation deficits fail to enhance or reduce emotions according to motivational and contextual information, thereby using strategies such as rumination and worry (in comparison with attention, acceptance, decentering, and reappraisal as elaborated emotion regulation strategies) in an attempt to escape from experiencing unwanted internal feelings. Therefore, they fail to implement valued and goaldirected behaviors [16].

This is the first study, which examined the emotion dysregulation model of distress disorders via structural equation modeling, and it may shed light on the extent, to which variables play a role in this comorbidity. Furthermore, the delineating component of emotion dysregulation models provides initial supports for looking deeper into motivational factors and strong evidence for assessing Emotion Regulation Therapy (ERT) in future studies. Consistent with that, in this study, our main hypothesis stated that emotion regulation strategies (attention, acceptance, decentering, and reappraisal) mediate the relationship between motivation (emotionality and safety) and distress symptoms (rumination, worry, MDD, and GAD).

\section{Materials and Methods}

The participants were recruited from a community sample in Tehran, Iran, through convenience sampling method. Of 550 individuals, who filled in the questionnaires, 42 participants were excluded because of missing data (more than 5\%), and 508 individuals, including 233(45.9\%) males and 275(54.1\%) females underwent the analysis. Their Mean \pm SD age was $35.24 \pm 10.74$. Regarding the marital status, $160(31.5 \%), 334(65.7 \%)$, $6(1.2 \%)$ were single, married, and divorced, respectively; $8(1.6 \%)$ of the participants did not identify their marital status. In terms of education, 76(15\%), 213 (41.9\%), 147(29\%), 58(11.4\%), and 14(2.8\%) were in the levels of junior high school, diploma, bachelor, master, and $\mathrm{PhD}$, respectively.

Before gathering the data, all participants were informed of the study purpose and were assured about the confidentiality of the study; then, they signed written informed consent to participate in the study. The participants filled in 9 questionnaires for almost 2 hours. They were asked to fill in questionnaires of Affect Intensity Measure (AIM) and Sensitivity to Punishment and Sensitivity to Reward (SPORQ) to assess the 
negative emotional intensity and safety/punishment, respectively. The Attentional Control Scale (ACS), Difficulties in Emotion Regulation Scale (DERS), Experiences Questionnaire (EQ), and Emotion Regulation Questionnaire (ERQ) were used to assess attention, acceptance, decentring, and reframing as emotion regulation strategies, respectively. The Beck Depression Questionnaire (BDI-II), Generalized Anxiety Disorder 7-item Scale (GAD-7), Penn State Worry Questionnaire (PSWQ), and the Ruminative Response Scale (RRS) were used to assess MDD/depression symptoms, GAD symptoms, worry, and rumination, respectively.

It is worth mentioning that all measures have agreeable validity and reliability in the Persian version, which will be explained below in more detail. The inclusion criteria included the age range of (20-59) years, being resident in Tehran, and having the minimum level of education (junior high school).

AIM is a self-report 40 -item questionnaire with a 6-point Likert scale (never=1 to always=6) [27]. AIM assesses individual differences in affective reactions to typical life situations, as a strong dimension of personality. The 10-item subscale that assesses negative emotional intensity has been used in the present study based on the reliability analysis; the Cronbach's alpha of 0.80 was retained for AIM, and the internal consistency of negative emotional intensity was 0.70 [27-29].

SPORQ is a self-report 48-item questionnaire with yes and no response format and two subscales, including sensitivity to punishment and sensitivity to reward as a personality dimension [30]. Sensitivity to punishment is used to assess safety. The internal consistency of this subscale was 0.84 [31]. The internal consistency of punishment was 0.84 .

ACS is a self-report 20-item questionnaire with a 4-point Likert scale (1=almost never to $4=$ always) that assesses attentional control and attentional shifting [32]. The internal consistency of the total score is 0.88 , and the test-retest reliability for ACS items varies from 0.45 to $0.73[32,33]$. Based on the reliability analysis among the Iranian population, the Cronbach's alpha of 0.77 was obtained [34].

DERS is a self-report 36-item scale based on a 5-Likert ranging from 1 (almost never) to 5 (almost always) and assesses individual's general inclinations for emotion regulation across 6 facets [35]. DERS demonstrates high internal consistency ( $\alpha=0.80$ for each subscale) and good test-retest reliability of 0.88 [35]. The internal consistency of this subscale was 0.85 .

EQ is a self-report 20-item questionnaire that is based on a 7-Likert scale ranging from 1 (never) to 7 (all the time). Eleven items decentering subscale was used in this study. The internal consistency and test-retest reliability of this subscale were $\alpha=0.89$ and ( $r=0.87$ ), respectively [36].

ERQ is a 10-item self-report questionnaire with a 7-Likert point scale. ERQ consists of 2 subscales, namely reappraisal, and suppression. The internal consistency of reappraisal was 0.79 , and the internal consistency of the Iranian version was $0.75[37,38]$. The internal consistency of suppression was 0.80 .

BDI-II is a self-report 21-item questionnaire that assesses the severity of the depressive disorder. Each item is scored from 0 to 3 . The internal consistency values of $\mathrm{BDI}-\mathrm{II}$ in psychiatric and non-psychiatric populations are 0.86 and 0.81 , respectively [39]. The internal consistency of BDI-II in the present study was 0.86 .

GAD-7 scale is a self-report 7-item scale that assesses the severity of generalized anxiety disorder and is answered on a Likert scale ranging from 0 (not at all) to 3 (nearly every day) [40]. The internal consistency and test-retest reliability of this scale were $(\alpha=0.92)$ and $(r=0.83)$, respectively. The internal consistency of GAD-7 in the present study was 0.89 .

PSWQ is a 16-item self-report questionnaire assessing worry on a 5-point Likert scale. Its internal consistency is 0.93 and demonstrates the test-retest reliability of 0.74 to 0.93 [41]. The internal consistency of PSWQ in the present study was 0.86 .

RRS is a 22-item self-report questionnaire that evaluates the tendency of an individual to contemplate in response to depressed mood and is answered on a 4-point Likert scale [42]. The internal consistency of RRS is 0.89 , and it was 0.91 in the present study [43].

The confirmatory factor analysis of all measures was assessed before the data analysis. All measures had adequate fitness. Structural Equation Modeling (SEM) was done to analyze the data. Before analysis, the database was assessed to meet the presumptions of SEM as multicollinearity, normality, and linearity. After meeting all the assumptions, SEM was run. Correlation and descriptive statistics were used to assess the assumptions and descriptive findings. SPSS V. 23 and AMOS 23 were used to analyze the data. Safety and emotionality 


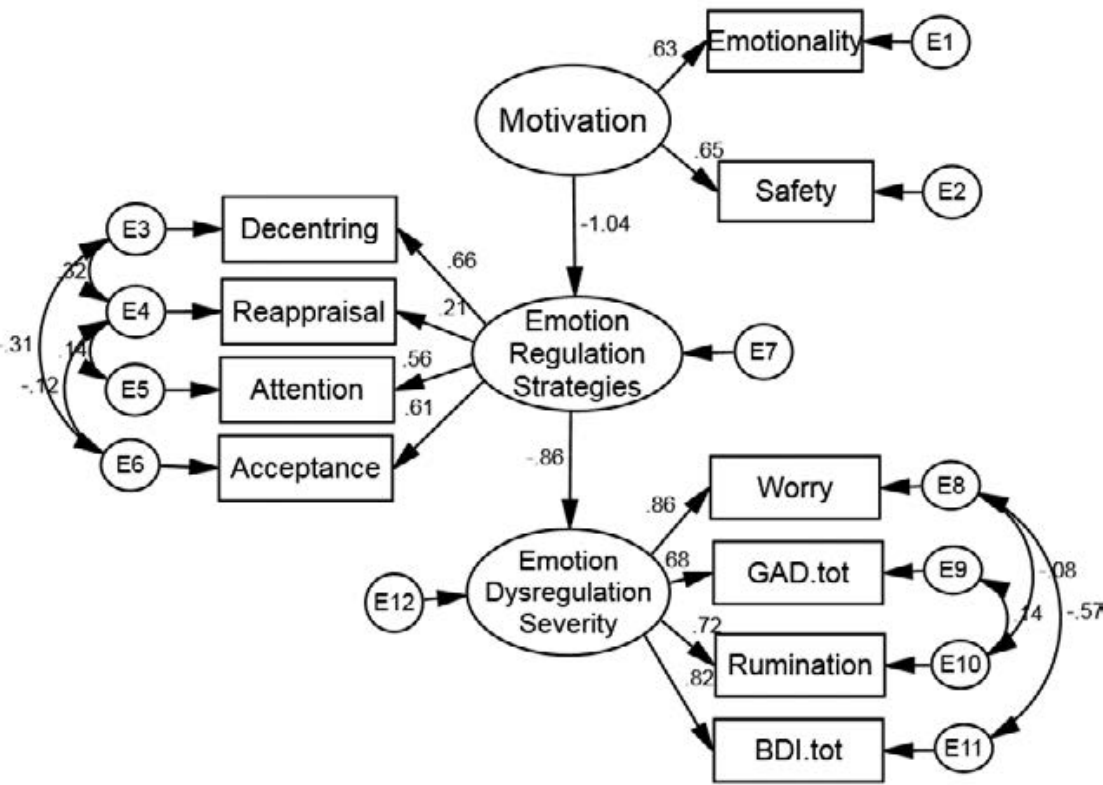

Figure 1. Emotion regulation model of distress symptom

were loaded onto a latent motivation factor. Attention, acceptance, decentering, and reappraisal were loaded onto latent emotion regulation strategies factor, and rumination, worry, MDD, and GAD were loaded onto a distress symptoms factor.

\section{Results}

Table 1 presents the descriptive statistics of the measured variables. Table 2 presents the correlation matrix of variables. There are significant relationships between all variables except for reframing, emotionality, and attention. The model fitness was acceptable $\left(\chi^{2}=64.51, d f=26, \chi^{2} / d f=2.48, P<0.001, C F I=0.97\right.$, $\mathrm{GFI}=0.97, \mathrm{PCFI}=0.56, \mathrm{RMSEA}=0.05$. $\mathrm{CFI}, \mathrm{GFI}$ is $>0.95$, $\mathrm{PCFI}$ is $>0.50$, and RMSEA is $<0.08$ ). The parameters indicate the good and acceptable fitness of the model. Thus, the results of the present study demonstrate the direct mediating role of emotion regulation strategies (attention, acceptance, decentering, and reframing) and the indirect role of motivation measures (negative emotional intensity/emotionality and safety/pun-

Table 1. Descriptive statistics of the measured variables

\begin{tabular}{cccc}
\hline Variables & Mean \pm SD & Skewness & Kurtosis \\
\hline Emotionality & $38.06 \pm 7.25$ & 0.24 & 0.36 \\
Safety & $10.15 \pm 5.43$ & 0.22 & -0.77 \\
\hline Attention & $44.36 \pm 6.72$ & 0.01 & 0.10 \\
\hline Acceptance & $22.08 \pm 5.31$ & -0.46 & -0.47 \\
\hline Decentering & $35.24 \pm 7.17$ & -0.16 & -0.02 \\
\hline Reframing & $25.29 \pm 6.08$ & -0.17 & -0.03 \\
MDD & $13.36 \pm 10.44$ & 0.90 & 0.31 \\
GAD & $7.97 \pm 4.99$ & 0.51 & -0.02 \\
Worry & $46.20 \pm 10.47$ & 0.25 & 0.08 \\
\hline Rumination & $36.45 \pm 9.22$ & 0.43 & 0.10 \\
\hline
\end{tabular}


Table 2. Correlation matrix of the measured variables

\begin{tabular}{|c|c|c|c|c|c|c|c|c|c|c|}
\hline Variables & 1 & 2 & 3 & 4 & 5 & 6 & 7 & 8 & 9 & 10 \\
\hline 1.AIM & 1 & - & - & - & - & - & - & - & - & - \\
\hline 2. PS & $0.40^{*}$ & 1 & - & - & - & - & - & - & - & - \\
\hline 3. ACS & $-0.35^{*}$ & $-0.43^{*}$ & 1 & - & - & - & - & - & - & - \\
\hline 4. $\mathrm{ACT}$ & $-0.37^{*}$ & $-0.41^{*}$ & $0.35^{*}$ & 1 & - & - & - & - & - & - \\
\hline 5. EQ & $-0.46^{*}$ & $-0.39^{*}$ & $0.34^{*}$ & $0.21^{*}$ & 1 & - & - & - & - & - \\
\hline 6. ERQ & 0.07 & $-0.17^{*}$ & $0.22^{*}$ & 0.03 & $0.37^{*}$ & 1 & - & - & - & - \\
\hline 7. BDI & $0.43^{*}$ & $0.47^{*}$ & $-0.31^{*}$ & $-0.42^{*}$ & $-0.52^{*}$ & $-0.20^{*}$ & 1 & - & - & - \\
\hline 8. GAD & $0.41^{*}$ & $0.35^{*}$ & $-0.31^{*}$ & $-0.39^{*}$ & $-0.38^{*}$ & $-0.09^{*}$ & $0.56^{*}$ & 1 & - & - \\
\hline 9. PSWQ & $0.49^{*}$ & $0.51^{*}$ & $-0.43^{*}$ & $-0.44^{*}$ & $-0.46^{*}$ & -0.16 & $0.53^{*}$ & $0.57^{*}$ & 1 & - \\
\hline 10. RRS & $0.38^{*}$ & $0.42^{*}$ & $-0.33^{*}$ & $-0.45^{*}$ & $-0.34^{*}$ & $-0.08^{*}$ & $0.59^{*}$ & $0.56^{*}$ & $0.58^{*}$ & 1 \\
\hline
\end{tabular}

AIM: Negative emotional intensity; PS: Safety; ACS: Attention; EQ: Decentering; ERQ: Reframing; BDI: Depressionp; PSWQ: Worry; RRS: Rumination

ishment sensitivity) in predicting distress symptoms (MDD, GAD, worry, and rumination).

Figure 1 represents the model with standard estimates of each measure with its latent component. Reappraisal and decentering had the least and most path weight on the emotion regulation strategies factor, respectively. Other variables path weight on motivation and distress symptoms factors were almost the same.

\section{Discussion}

The results of SEM analyses showed that the hypothesized model had an adequate fitness and the motivation factors (emotionality and safety) predicted distress symptoms (MDD, GAD, worry, and rumination) via emotion regulation strategies (attention, acceptance, decentering, and reframing). Furthermore, the mediating role of emotion regulation deficits in psychopathology and treatment of emotional disorders have been implicated in previous studies [25, 44, 45]; these findings show that the emotion dysregulation model can work beyond cultural limitations and biological mechanisms that may take part in its function.

Some researchers suggest that the heightened negative reactivity and punishment sensitivity in combination with emotion regulation deficits predispose individuals to anxiety and depression disorders [46, 47]. However, in some studies, the heightened negative emotion and sensitivity to punishment/safety motivation have been proposed as non-specific vulnerabilities, indicating the crucial role of personality factors in predisposing individuals to psychiatric disorders $[48,49]$.

In our study, the non-significant relationships of reappraisal/reframing with emotionality and attention and low standard estimates of this measure with its latent component need more explanations. Firstly, typicallymaladaptive emotion regulation strategies are more strongly associated with psychopathology than adaptive emotion regulation strategies as reappraisal [50]. Secondly, reappraisal may be a multidimensional construct; each of dimensions may differently operate and have a distinct relationship with psychopathology [51].

Thirdly, the time (initially or at the end) of presenting the emotion regulation strategy like reappraisal in the process of emotion regulation has divergent functional or dysfunctional effects [52]. Fourthly, according to the compensatory hypothesis, adaptive strategies have a negative association with psychopathology symptoms only at the high levels of maladaptive strategies [53]. Finally, the role of context in the functional and dysfunctional use of each emotion regulation strategy should be considered entirely important [54]. Explanations, as mentioned above, should be considered in interpreting the results of the present study. 
To explain the mechanism of the emotion dysregulation model of distress symptoms in this study, we can say that the heightened sensitivity to punishment or safety and emotionality makes individuals with distress symptoms more prone to use more maladaptive or less adaptive emotion regulation strategies; this would lead to more worry and rumination, thereby creating depression and GAD symptoms. Thus, a vicious cycle, which creates more distress symptoms, make the individuals susceptible to more motivation impairment. Our results provide initial support for the emotional dysregulation model of distress symptoms.

Some limitations should be considered in the interpretation of our study findings. Firstly, contextual learning is one of the most important components of this model that we did not assess in the present study, because of the lack of instrument for evaluating this component. Secondly, we examined emotion dysregulation model with self-report questionnaires, and the results may have defaced with answer biases and overlooking emotional concepts well.

Thirdly, although the study sample was from a community and better than student samples, it could not be generalized to clinical settings. Finally, given the notable role of context in the adjustment and maladjustment action of each emotion regulation strategy, the present study failed to examine that. The context may determine the adaptability and mal-adaptability of the range of emotion regulation strategies and even the intensity of emotion and examining context may provide somehow different results in relation to the present findings. For example, the relation of emotion regulation strategies may change according to the context. Moreover, the future area of affective science may benefit more from multidimensional assessments, using biological and genetic indices that emphasize contextual learning and individual differences in implementing emotion regulation strategies according to different contexts. Finally, future studies should investigate the emotion dysregulation model in clinical samples.

\section{Conclusions}

The findings of this study support the mediating role of emotion regulation strategies in the psychopathology of distress symptoms and a good fitness of emotion dysregulation model of distress symptoms and possibly its parallel psychological treatment (ERT). It seems that personality dimensions like safety motivation and emotional intensity could affect distress symptoms indirectly via emotion regulation strategies. Furthermore, instead of focusing on categorizing emotion regulation strategies in two distinct adaptive and maladaptive classes, it is better to highlight the contextual utility of them and developing some experiments to assess them, especially for confusing and inconsistent functionality of some emotion regulation strategies such as reappraisal.

\section{Ethical Considerations}

\section{Compliance with ethical guidelines}

All ethical principles were observed in accordance with the principles of working with human subjects. The study was approved by the Ethics Committee of the University of Social Welfare and Rehabilitation Sciences (IR. USWR.REC.1394.291).

\section{Funding}

This research did not receive any specific grant from funding agencies in the public, commercial, or not for profit sectors.

\section{Authors' contributions}

Conceptualization: Imaneh Abasi, Latif Moradveisi, Mohammad Ebrahim Sarichloo, Maryam Aslzaker, Sadegh Nasri; Methodology: Imaneh Abasi, Latif Moradveisi; Investigation: Imaneh Abasi, Latif Moradveisi, Mohammad Ebrahim Sarichloo, Maryam Aslzaker, Sadegh Nasri; Writing-original draft: : Imaneh Abasi, Latif Moradveisi; Writing-review \& editing: Imaneh Abasi, Latif Moradveisi, Mohammad Ebrahim Sarichloo, Maryam Aslzaker, Sadegh Nasri; Funding acquisition: Imaneh Abasi, Latif Moradveisi, Mohammad Ebrahim Sarichloo, Maryam Aslzaker, Sadegh Nasri; Resources: Imaneh Abasi, Latif Moradveisi, Mohammad Ebrahim Sarichloo, Maryam Aslzaker, Sadegh Nasri; Supervision: Imaneh Abasi, Latif Moradveisi.

\section{Conflict of interest}

The authors declare no conflict of interest.

\section{References}

[1] Kessler RC, Chiu WT, Demler O, Walters EE. Prevalence, severity, and comorbidity of 12-month DSM-IV disorders in the National Comorbidity Survey replication. Archives of General Psychiatry. 2005 62(6):617-27. [DOI:10.1001/archpsyc.62.6.617] [PMID] [PMCID]

[2] Grant BF, Hasin DS, Stinson FS, Dawson DA, Ruan WJ, Goldstein RB, et al. Prevalence, correlates, co-morbidity, and comparative disabil- 
ity of DSM-IV generalized anxiety disorder in the USA: Results from the national epidemiologic survey on alcohol and related conditions. Psychological Medicine. 2005; 35(12):1747-59. [DOI:10.1017/ S0033291705006069] [PMID]

[3] Kessler RC, Gruber M, Hettema JM, Hwang I, Sampson N, Yonkers KA. Co-morbid major depression and generalized anxiety disorders in the National comorbidity survey follow-up. Psychological Medicine. 2008; 38(03):365-74. [DOI:10.1017/S0033291707002012] [PMID] [PMCID]

[4] Gorwood P. Generalized anxiety disorder and major depressive disorder comorbidity: An example of genetic pleiotropy? European Psychiatry. 2004; 19(1):27-33. [DOI:10.1016/j.eurpsy.2003.10.002] [PMID]

[5] Kendler KS, Gardner CO, Gatz M, Pedersen NL. The sources of comorbidity between major depression and generalized anxiety disorder in a Swedish national twin sample. Psychological Medicine. 2007; 37(03):453-62. [DOI:10.1017/S0033291706009135] [PMID]

[6] Kendler KS, Davis CG, Kessler RC. The familial aggregation of common psychiatric and substance use disorders in the National Comorbidity Survey: A family history study. The British Journal of Psychiatry. 1997; 170(6):541-8. [DOI:10.1192/bjp.170.6.541] [PMID]

[7] Regier DA, Rae DS, Narrow WE, Kaelber CT, Schatzberg AF. Prevalence of anxiety disorders and their comorbidity with mood and addictive disorders. The British Journal of Psychiatry. 1998; 173(S34):24-8. [DOI:10.1192/S0007125000293483]

[8] Wittchen HU, Carter R, Pfister H, Montgomery S, Kessler R. Disabilities and quality of life in pure and comorbid generalized anxiety disorder and major depression in a national survey. International Clinical Psychopharmacology. 2000; 15(6):319-28. [DOI:10.1097/00004850-200015060-00002] [PMID]

[9] Hegel MT, Unützer J, Tang L, Areán PA, Katon W, Noël PH, et al. Impact of comorbid panic and posttraumatic stress disorder on outcomes of collaborative care for late-life depression in primary care. The American Journal of Geriatric Psychiatry. 2005; 13(1):48-58. [DOI:10.1097/00019442-200501000-00008] [PMID]

[10] Mittal D, Fortney JC, Pyne JM, Edlund MJ, Wetherell JL. Impact of comorbid anxiety disorders on health-related quality of life among patients with major depressive disorder. Psychiatric Services. 2006; 57(12):1731-7. [DOI:10.1176/ps.2006.57.12.1731] [PMID]

[11] Johansson R, Carlbring P, Heedman A, Paxling B, Andersson G. Depression, anxiety and their comorbidity in the Swedish general population: Point prevalence and the effect on health-related quality of life. PeerJ. 2013; 1:e98. [DOI:10.7717/peerj.98] [PMID] [PMCID]

[12] Fava M, Rush AJ, Alpert JE, Balasubramani G, Wisniewski SR, Carmin $\mathrm{CN}$, et al. Difference in treatment outcome in outpatients with anxious versus nonanxious depression: A STAR* D report. American Journal of Psychiatry. 2008; 165(3):342-51. [DOI:10.1176/appi ajp.2007.06111868] [PMID]

[13] Jazaieri H, Morrison AS, Goldin PR, Gross JJ. The role of emotion and emotion regulation in social anxiety disorder. Current Psychiatry Reports. 2015; 17(1):1-9. [DOI:10.1007/s11920-014-0531-3] [PMID]

[14] McLaughlin KA, Mennin DS, Farach FJ. The contributory role of worry in emotion generation and dysregulation in generalized anxiety disorder. Behaviour Research and Therapy. 2007; 45(8):173552. [DOI:10.1016/j.brat.2006.12.004] [PMID]

[15] Mennin DS, Fresco DM. Advancing emotion regulation perspectives on psychopathology: The challenge of distress disorders.
Psychological Inquiry. 2015; 26(1):80-92. [DOI:10.1080/104784 0X.2015.969624] [PMID] [PMCID]

[16] Mennin DS, Fresco DM. Emotion regulation therapy. Handbook of Emotion Regulation. New York: Guilford publications; 2014.

[17] Gross JJ. Handbook of emotion regulation. New York: Guilford publications; 2013

[18] Berking M, Wirtz CM, Svaldi J, Hofmann SG. Emotion regulation predicts symptoms of depression over five years. Behaviour Research and Therapy. 2014; 57:13-20. [DOI:10.1016/j. brat.2014.03.003] [PMID]

[19] Watson D. Rethinking the mood and anxiety disorders: A quantitative hierarchical model for DSM-V. Journal of Abnormal Psychology. 2005; 114(4):522. [DOI:10.1037/0021-843X.114.4.522] [PMID]

[20] Bullis JR, Sauer-Zavala S, Bentley KH, Thompson-Hollands J, Car $\mathrm{JR}$, Barlow DH. The unified protocol for transdiagnostic treatment of emotional disorders preliminary exploration of effectiveness for group delivery. Behavior Modification. 2015; 39(2):295-321. [DOI:10.1177/0145445514553094] [PMID]

[21] Mennin DS, Holaway RM, Fresco DM, Moore MT, Heimberg RG. Delineating components of emotion and its dysregulation in anxiety and mood psychopathology. Behavior Therapy. 2007; 38(3):284-302. [DOI:10.1016/j.beth.2006.09.001] [PMID]

[22] Ormel J, Jeronimus BF, Kotov R, Riese H, Bos EH, Hankin B, et al. Neuroticism and common mental disorders: Meaning and utility of a complex relationship. Clinical Psychology Review. 2013; 33(5):686-97. [DOI:10.1016/j.cpr.2013.04.003] [PMID] [PMCID]

[23] Barlow DH, Sauer-Zavala S, Carl JR, Bullis JR, Ellard KK. The nature, diagnosis, and treatment of neuroticism: Back to the future. Clinical Psychological Science. 2014; 2(3):344-65. [DOI:10.1177/2167702613505532]

[24] Mennin DS, McLaughlin KA, Flanagan TJ. Emotion regulation deficits in generalized anxiety disorder, social anxiety disorder, and their co-occurrence. Journal of Anxiety Disorders. 2009; 23(7):866-71. [DOI:10.1016/j.janxdis.2009.04.006] [PMID] [PMCID]

[25] Mohammadkhani P, Abasi I, Pourshahbaz A, Mohammadi A, Fatehi M. The role of neuroticism and experiential avoidance in predicting anxiety and depression symptoms: Mediating effect of emotion regulation. Iranian Journal of Psychiatry and Behavioral Sciences. 2016; 10(3): e5047. [DOI:10.17795/ijpbs-5047] [PMID] [PMCID]

[26] Desrosiers A, Vine V, Klemanski DH, Nolen-Hoeksema S. Mindfulness and emotion regulation in depression and anxiety: Common and distinct mechanisms of action. Depression and Anxiety. 2013 30(7):654-61. [DOI:10.1002/da.22124] [PMID] [PMCID]

[27] Larsen RJ, Diener E, Emmons RA. Affect intensity and reactions to daily life events. Journal of Personality and Social Psychology. 1986; 51(4):803-14. [DOI:10.1037/0022-3514.51.4.803]

[28] Larsen RJ, Diener E, Cropanzano RS. Cognitive operations associated with individual differences in affect intensity. Journal of Personality and Social Psychology. 1987; 53(4):767-74. [DOI:10.1037/0022 3514.53.4.767] [PMID]

[29] Diener E, Larsen RJ, Levine S, Emmons RA. Intensity and frequency: Dimensions underlying positive and negative affect. Journal of Personality and Social Psychology. 1985; 48(5):1253-65. [DOI:10.1037/0022-3514.48.5.1253] [PMID]

[30] Torrubia R, Avila C, Moltó J, Caseras X. The Sensitivity to Punishment and Sensitivity to Reward Questionnaire (SPSRQ) as a meas 
ure of gray's anxiety and impulsivity dimensions. Personality and Individual Differences. 2001; 31(6):837-62. [DOI:10.1016/S01918869(00)00183-5]

[31] Franken IH, Muris P. Gray's impulsivity dimension: A distinction between reward sensitivity versus rash impulsiveness. Personality and Individual Differences. 2006; 40(7):1337-47. [DOI:10.1016/j. paid.2005.11.016]

[32] Derryberry D, Reed MA. Anxiety-related attentional biases and their regulation by attentional control. Journal of Abnormal Psychology. 2002; 111(2):225-36. [DOI:10.1037//0021-843X.111.2.225] [PMID]

[33] Fajkowska M, Derryberry D. Psychometric properties of Attentional Control Scale: The preliminary study on a polish sample. Polish Psychological Bulletin. 2010; 41(1):1-7. [DOI:10.2478/s10059010-0001-7]

[34] Abasi I, Mohammadkhani P, Pourshahbaz A, Dolatshahi B. The psychometric properties of attentional control scale and its relationship with symptoms of anxiety and depression: A study on Iranian population. Iranian Journal of Psychiatry. 2017; 12(2):109-17. [PMID] [PMCID]

[35] Gratz KL, Roemer L. Multidimensional assessment of emotion regulation and dysregulation: Development, factor structure, and initia validation of the difficulties in emotion regulation scale. Journal of Psychopathology and Behavioral Assessment. 2004; 26(1):41-54 [DOI:10.1023/B:JOBA.0000007455.08539.94]

[36] Fresco DM, Moore MT, van Dulmen MH, Segal ZV, Ma SH, Teasdale JD, et al. Initial psychometric properties of the experiences questionnaire: Validation of a self-report measure of decentering. Behavior Therapy. 2007; 38(3):234-46. [DOI:10.1016/j. beth.2006.08.003] [PMID]

[37] Gross JJ, John OP. Individual differences in two emotion regulation processes: Implications for affect, relationships, and well-being Journal of Personality and Social Psychology. 2003; 85(2):348-62. [DOI:10.1037/0022-3514.85.2.348] [PMID]

[38] Abasi I, Fata L, Sadeghi M, Banihashemi S, Mohammadee A. A Comparison of transdiagnostic components in generalized anxiety disorder, unipolar mood dDisorder and nonclinical population. International Journal of Psychology and Behavioral Sciences. 2013; 7(12):803-11.

[39] Beck AT, Steer RA, Carbin MG. Psychometric properties of the Beck depression inventory: Twenty-five years of evaluation. Clinical Psychology Review. 1988; 8(1):77-100. [DOI:10.1016/02727358(88)90050-5]

[40] Spitzer RL, Kroenke K, Williams JB, Löwe B. A brief measure for assessing generalized anxiety disorder: The GAD-7. Archives of Internal Medicine. 2006; 166(10):1092-7. [DOI:10.1001/ archinte.166.10.1092] [PMID]

[41] Meyer TJ, Miller ML, Metzger RL, Borkovec TD. Development and validation of the Penn State worry questionnaire. Behaviour Research and Therapy. 1990; 28(6):487-95. [DOI:10.1016/0005 7967(90)90135-6]

[42] Nolen-Hoeksema S. Responses to depression and their effects on the duration of depressive episodes. Journal of Abnormal Psychology. 1991; 100(4):569-82. [DOI:10.1037/0021-843X.100.4.569]

[43] Nolen-Hoeksema S, Parker LE, Larson J. Ruminative coping with depressed mood following loss. Journal of Personality and Social Psychology. 1994; 67(1):92-104. [DOI:10.1037/0022-3514.67.1.92] [PMID]
[44] Hamill TS, Pickett SM, Amsbaugh HM, Aho KM. Mindfulness and acceptance in relation to behavioral inhibition system sensitivity and psychological distress. Personality and Individual Differences. 2015; 72:24-9. [DOI:10.1016/j.paid.2014.08.007]

[45] Tortella-Feliu M, Balle M, Sesé A. Relationships between negative affectivity, emotion regulation, anxiety, and depressive symptoms in adolescents as examined through structural equation modeling. Journal of Anxiety Disorders. 2010; 24(7):686-93. [DOI:10.1016/j. janxdis.2010.04.012] [PMID]

[46] Pickett SM, Bardeen JR, Orcutt HK. Experiential avoidance as a moderator of the relationship between behavioral inhibition system sensitivity and posttraumatic stress symptoms. Journal of Anxiety Disorders. 2011; 25(8):1038-45. [DOI:10.1016/j. janxdis.2011.06.013] [PMID]

[47] Macatee RJ, Cougle JR. The roles of emotional reactivity and tolerance in generalized, social, and health anxiety: A multimethod exploration. Behavior Therapy. 2013; 44(1):39-50. [DOI:10.1016/j. beth.2012.05.006] [PMID]

[48] Hughes KA, Moore RA, Morris PH, Corr PJ. Throwing light on the dark side of personality: Reinforcement sensitivity theory and primary/secondary psychopathy in a student population. Personality and Individual Differences. 2012; 52(4):532-6. [DOI:10.1016/j. paid.2011.11.010

[49] Izadpanah S, Schumacher M, Bähr A, Stopsack M, Grabe HJ, Barnow S. A 5-year longitudinal study of the adolescent reinforcement sensitivity as a risk factor for anxiety symptoms in adulthood: Investigating the indirect effect of cognitive emotion regulation. Personality and Individual Differences. 2016; 95:68-73. [DOI:10.1016/j. paid.2016.02.021

[50] Aldao A, Nolen-Hoeksema S, Schweizer S. Emotion-regulation strategies across psychopathology: A meta-analytic review. Clinical Psychology Review. 2010; 30(2):217-37. [DOI:10.1016/j. cpr.2009.11.004] [PMID]

[51] McRae K, Ciesielski B, Gross JJ. Unpacking cognitive reappraisal: Goals, tactics, and outcomes. Emotion. 2012; 12(2):250-5 [DOI:10.1037/a0026351] [PMID]

[52] Sheppes G, Catran E, Meiran N. Reappraisal (but not distraction) is going to make you sweat: Physiological evidence for self-control effort. International Journal of Psychophysiology. 2009; 71(2):91-6. [DOI:10.1016/j.ijpsycho.2008.06.006] [PMID]

[53] Aldao A, Nolen-Hoeksema S. When are adaptive strategies most predictive of psychopathology? Journal of Abnormal Psychology. 2012; 121(1):276-81. [DOI:10.1037/a0023598] [PMID]

[54] Aldao A. The future of emotion regulation research capturing context. Perspectives on Psychological Science. 2013; 8(2):155-72. [DOI:10.1177/1745691612459518] [PMID] 